\title{
The Assessment of the Abrasiveness for Resin Composite Finishing and Polishing Systems
}

\author{
Bora Korkut $^{1}$, Tuna Unal ${ }^{2}$ \\ ${ }^{1}$ Department of Restorative Dentistry, Faculty of Dentistry, Marmara University, Istanbul, Turkey \\ ${ }^{2}$ Department of Restorative Dentistry, Faculty of Dentistry, Yeditepe University, Istanbul, Turkey \\ Correspondence Author: Bora Korkut \\ E-mail: bora.korkut@marmara.edu.tr
}

Received: $02.01 .2021 \quad$ Accepted: 26.07 .2021

\begin{abstract}
Objective: This study was aimed to assess the abrasiveness of 4 composite finishing and polishing systems, on 2 nano-hybrid composite materials.

Methods: Fourty samples were prepared using Tetric EvoCeram BulkFill and IPS Empress Direct composites (Ivoclar Vivadent, Schaan, Lichtenstein). Each group was divided into 4 subgroups (Sof-Lex Disc, 3M, MN, USA; Enhance/Pogo, Dentsply, Konstanz, Germany; OptraGloss, Ivoclar Vivadent; Twist Dia, Kuraray, Tokyo, Japan). Finishing and polishing systems were performed at one side, for 30 s regarding each step. Initial (t0) and final (t1) thicknesses were measured with a micrometer (ME-DI-MIC-25-50-LD Digital External Micrometer, Machine DRO, Hoddesdon, UK). Two-way Anova test and Tukey HSD were performed for multiple comparisons, according to the t1-t0 values. Deem significance was set at $p<0,05$.

Results: IPS Empress Direct composite presented significantly a greater level of abrasion $(52.85 \pm 42.26)$ than Tetric Evo Ceram BulkFill ( $p<0.001)$. Significantly a greater level of abrasiveness was observed for Sof-Lex Disc system (91.25 \pm 47.22$)$ among all finishing and polishing materials $(p<0.001)$. There was no significant differences in abrasiveness, between Enhance/Pogo - Optragloss $(p=0.859)$, Enhance/Pogo - Twist Dia $(\mathrm{p}=0.891)$, and Twist Dia - Optragloss $(\mathrm{p}=0.440)$.

Conclusion: Both the type of composite and the finishing and polishing material were considered effective factors for abrasion. The greatest level of abrasiveness was observed for Sof-Lex Disc system ( $91 \mu \mathrm{m}$ on average). The abrasiveness for 2-step systems was similar and ranged between 24-36 $\mu \mathrm{m}$ on average. IPS Empress Direct presented a greater level of abrasion on equal terms of finishing and polishing.

Keywords: Abrasiveness, level of abrasion, composite, finishing, polishing.
\end{abstract}

\section{INTRODUCTION}

The quality of finishing and polishing procedures is directly related to the longevity of a composite restoration. Accordingly, manufacturers have introduced numerous systems for composite finishing and polishing procedures. Finishing is defined as gross contouring or reduction to obtain the required restoration morphology while polishing refers to the reduction in roughness and scratches typically created by the finishing instruments (1). Proper finishing and polishing procedures in direct composite restorations are necessary for long-lasting, esthetic result. Lack of these procedures may lead to tactile perception by the patient and plaque accumulation, thereby gingival irritation, staining, and secondary caries lesions (2-4). Previously, $0.2 \mu$ surface roughness was reported as the threshold value to avoid bacterial accumulation (5). Also, it was shown that mechanical properties have a positive correlation with wear resistance, both can be decreased by unpolished restorations $(6,7)$.
Finishing and polishing procedures are material - and techniquesensitive. The filler content of resin-based composites and the type of finishing and polishing systems used to influence the surface roughness and staining of restoration (1). Whereas, it was reported that the difference in polishability between composite materials is more significant compared to the difference between polishing systems (4). Also, the composite materials polished with finishing systems of the same manufacturer presented less surface roughness and staining, previously (8). Higher surface gloss can be maintained if the operator spends more time in finishing and polishing procedures (4). Contouring and re-shaping of the final restoration are generally performed with diamond or tungsten carbide burs and a more regular surface was reported for tungsten carbide burs compared to the diamond burs (9). However, some operators use polishing systems for this step (4).

Different shapes of finishing and polishing materials have been introduced to provide an effective application for different 
anatomical forms of restorations. These shapes include flame-shaped, points, cups, flexible discs, lenses, brushes, wheels, and spiral wheels in different sizes (4). In addition, they can be made of various materials, such as rubber, silicone, polyurethane, and rubber. To enhance the polishing effect, diamond and aluminum oxide particles are generally embedded in the material (5). Most recently, materials for both composite and ceramic surface polishing were also introduced.

The press-on force is another important parameter influencing the effectiveness while using the finishing and polishing materials (4). Some manufacturers (i.e., Kenda and Shofu) recommend operators to use a specific press-on force, $\leq 2 \mathrm{~N}(4,10)$. However, it is difficult for the operator to adjust the exact force during the clinical application. Many previous studies have used onedimensional force, however, the direction of the applied force to the surface is also important (4). Krejci et al. used $2.5 \mathrm{~N}$ onedimensional press-on force to evaluate abrasive bristles in vitro but didn't describe how the force was stabilized (6). The shape of the polishing material as well as the inclination of the surface to be polished are the parameters influencing the press-on force. In this respect, large flames and cups were reported to conduct greater forces compared to small flames and lenses (4). Heintze et al. presented a clinically simulated procedure using a 3D force sensor for evaluating the press-on forces for the first time in vitro (4). Each operator has a specific idea of the applied force when using a polishing instrument with a dental handpiece, yet it seems to be quite inaccurate.

There is a lack of knowledge regarding the level of abrasiveness of the finishing and polishing materials in literature. The level of abrasion depends on the press-on force, the type of the polishing material, and the material to be polished. Heintze et al. reported that higher forces result in either increase or decrease in the quality of surface polishing, depending on the material being polished (10). They concluded fine particle hybrid composites are press-on force-sensitive, while microfilled composites are not. Accordingly, a greater level of surface material removal, as well as a higher heat generation on the surface can be caused by higher press-on forces $(4,9)$. Moreover, it may also result in alterations in the optical properties of the restoration, as the width of the covering composite material changes. Therefore, it would be useful for the operator to know the average level of material removal from the surface during finishing and polishing procedures in clinical daily practice.

The aim of this in vitro was to evaluate the abrasiveness of various composite polishing systems on equal terms. The $h_{1}$ hypotheses were that; [1] the type of composite polishing system influences the level of abrasion, [2] the type of resin composite influences the level of abrasion.

\section{METHODS}

\subsection{Preparation and Distribution of the Specimens}

Two nano-hybrid resin composite materials, Tetric EvoCeram BulkFill (A1 body shade, Ivoclar Vivadent, Schaan, Lichtenstein) and IPS Empress Direct (A1 enamel shade, Ivoclar Vivadent,
Schaan, Lichtenstein) were used for the preparation of the composite samples (Table 1). A total of 80 disc-shaped samples of $4 \mathrm{~mm}$ in diameter and $2 \mathrm{~mm}$ in thickness were prepared using silicon molds. Resin composites were condensed into the silicon mold in two layers and mylar strips were placed over the top and the bottom surfaces to avoid oxygen inhibition layer formation (11-13). Excessive material was extruded by condensing the mold in between two glass slides. Polymerization of the samples was performed using a LED curing unit (Valo Grand, Ultradent Products, USA) at irradiation of $1000 \mathrm{~mW} / \mathrm{cm}^{2}$ for $40 \mathrm{~s}$ on each side. The light intensity was monitored with a radiometer during the preparation of the specimens (13). Each specimen was notched at two edges $180^{\circ}$ apart (single notch at one edge, double notch at the opposite edge) to maintain consistent orientation during the polishing procedures (14). Then the specimens were immersed in water at a constant $37^{\circ} \mathrm{C}$ for 24 hours using a dental incubator $(9,11,13,15)$.

Table 1. Contents and Manufacturers of Resin Composite Materials Finisging and Polishing Systems.

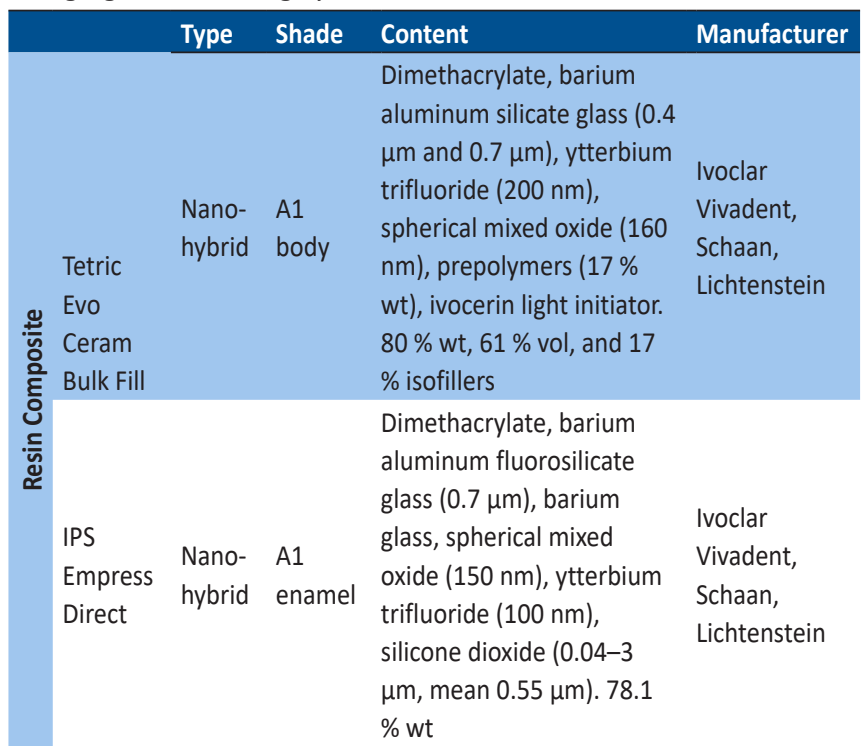

\begin{tabular}{|c|c|c|c|}
\hline \multirow{4}{*}{ 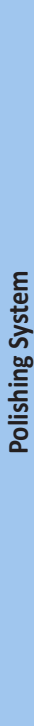 } & Sof-Lex Disc & $\begin{array}{l}\text { 4-step aluminum oxide } \\
\text { embedded flexible disc } \\
\text { system. Coarse }(55 \mu \mathrm{m}) \text {, } \\
\text { medium ( } 40 \mu \mathrm{m}) \text {, fine ( } 24 \\
\mu \mathrm{m}) \text {, and super fine }(8 \mu \mathrm{m}) \text {. }\end{array}$ & $\begin{array}{l}\text { 3M, St Paul, } \\
\text { MN, USA }\end{array}$ \\
\hline & Enhance/Pogo & $\begin{array}{l}\text { 2-step aluminum oxide } \\
\text { and diamond embedded } \\
\text { rubber cup system. } \\
\text { Enhance }(40 \mu \mathrm{m}) \text {, Pogo } \\
(7 \mu \mathrm{m}) \text {. }\end{array}$ & $\begin{array}{l}\text { Dentsply } \\
\text { Sirona, } \\
\text { Konstanz, } \\
\text { Germany }\end{array}$ \\
\hline & OptraGloss & $\begin{array}{l}\text { 2-step diamond embedded } \\
\text { cup and spiral wheel } \\
\text { system for both composite } \\
\text { and ceramic polishing. Cup } \\
\text { and spiral wheel. }\end{array}$ & $\begin{array}{l}\text { Ivoclar } \\
\text { Vivadent, } \\
\text { Schaan, } \\
\text { Lichtenstein }\end{array}$ \\
\hline & Twist Dia & $\begin{array}{l}\text { 2-step diamond embedded } \\
\text { spiral wheel system. Pre- } \\
\text { polisher }(14 \mu \mathrm{m}), \text { high- } \\
\text { shine polisher }(10 \mu \mathrm{m}) .\end{array}$ & $\begin{array}{l}\text { Kuraray } \\
\text { Noritake, } \\
\text { Tokyo, Japan }\end{array}$ \\
\hline
\end{tabular}


The initial evaluation of thickness $\left(t_{0}\right)$ for each sample was performed for 3 times by a single operator for each sample using an industrial type screw-type digital micrometer (0.001 $\mathrm{mm}$ ) with 25-50 $\mathrm{mm}$ measuring range (ME-DI-MIC-2550-LD Digital External Micrometer 25-50mm, Machine DRO, The Allendale Group Ltd., Hoddesdon, UK; Figure 1). This device was used as the control method for monitoring the quantitative dental hard tissue loss, previously $(16,17)$.

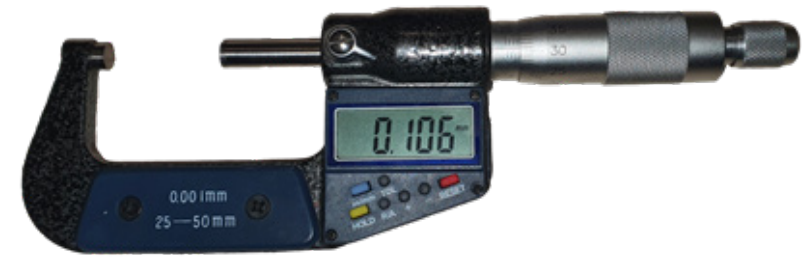

Figure 1. Digital Contact-Type Micrometer

\subsection{Finishing and Polishing Protocol}

The resin composite groups were divided into 4 polishing material subgroups randomly ( $n=10$ for each subgroup). SofLex Disc (3M, St. Paul, MN, USA), Enhance/Pogo (Dentsply Sirona, Konstanz, Germany), OptraGloss (Ivoclar Vivadent, Shaan, Lichtenstein), and Twist Dia (Kuraray Noritake, Tokyo, Japan) were used for the finishing and polishing procedures (Table 1). For each specimen, one side was selected and marked for the finishing and polishing (9). The selected surfaces were roughened with 600 and 800 grit sandpapers (Carbimet, Special Silicone Carbide Grinding Paper, IL, USA), respectively to generate standardized initial roughness for the surfaces $(12,18)$.

A preliminary study was undergone regarding the calibration of press-on force and micrometer measurements with two blind female operators using another 20 samples. A latchtype slow speed handpiece was used with the polishing materials attached (11). Also, both observers measured the thicknesses of 20 samples using the micrometer, before and after the abrasion procedures. After achieving a perfect interclass correlation for both measurement periods (0.999 and 1.000; Table 1), the real polishing procedures were initiated. Operator 1 was selected as the single operator to perform the surface roughening and the finishing and polishing procedures.

All samples were treated with the 4 different finishing and polishing systems (Twist Dia, Sof-Lex Disc, Enhance/Pogo, and OptraGloss) at $10.000 \mathrm{rpm}$, in dry conditions, by the same operator [Figure $2(A-D)$ ]. Each material in the systems was used for $30 \mathrm{~s}$ in the present study (19). The specimens were rotated (a quarter turn for every $5 \mathrm{~s}$ ) during the finishing and polishing procedures to equalize the surface contacts. The application was performed in various directions to the whole specimen surface for $30 \mathrm{~s}$. The specimens were rinsed and dried between steps to remove the polishing debris. Also, the finishing and polishing materials were renewed for each composite specimen (19).

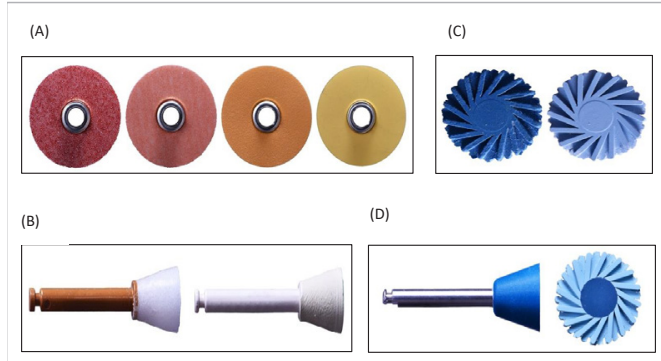

Figure $2(A-D)$. The Polishing Systems Used in the Study. (A) Sof-Lex Disc, (B) Enhance \& Pogo, (C) Twist Dia, (D) OptraGloss.

The four-step Sof-Lex Disc system includes 4 aluminum oxide $\left(\mathrm{Al}_{2} \mathrm{O}_{3}\right)$ embedded discs and each was used for $30 \mathrm{~s}$ on both sides at dry conditions $(14,20)$. The discs including thick to thin grains $(55 \mu \mathrm{m}, 40 \mu \mathrm{m}, 24 \mu \mathrm{m}$, and $8 \mu \mathrm{m})$ were used respectively for each specimen (11). The two-step Enhance/ Pogo system includes two $\mathrm{Al}_{2} \mathrm{O}_{3}$ and diamond embedded silicon cups (11) and each was used for $30 \mathrm{~s}$ on both sides at dry conditions. Enhance cups with $40 \mu \mathrm{m}$ grains were used first and followed by Pogo cups with $7 \mu \mathrm{m}$ grains (13). The two-step Twist Dia system includes two diamond-embedded spiral wheels and each was used for $30 \mathrm{~s}$ on both sides at dry conditions. The dark blue pre-polisher wheel including $14 \mu \mathrm{m}$ grains was used first and followed by the light blue high-shine polisher wheel including $10 \mu \mathrm{m}$ grains $(12,21)$. The two-step OptraGloss system includes one diamond-embeded cup and one diamond-embedded spiral wheel. Each was used for $30 \mathrm{~s}$ on both sides at dry conditions. The dark blue cup was used first and followed by the light blue spiral wheel.

The specimens were cleaned from debris and the final evaluation of thickness $\left(t_{1}\right)$ was performed by the same operator 3 times for each sample using the digital micrometer.

\subsection{Statistical Analysis}

Data were analyzed using IBM SPSS V23 software. The normality of data for the composites and the finishing and polishing materials was observed with the Shapiro Wilk test. The correlation between the two operators regarding the polishing procedures and the reliability of the calculations of the two observers were observed with ICC. The twoway Anova test was used for the evaluation of abrasion level according to the composites and polishing materials. Multiple comparisons were evaluated with Tukey HSD. Standard deviations were presented as average \pm S.D. Deem significance was set at $p<0,05$.

\section{RESULTS}

A perfect, positive correlation was observed between the two blinded observers for both observation periods $(p<0.001$ for each; Table 2). Therefore, the average values of the measurements of observer 1 were taken into consideration for the statistical analyses. 
Table 2. ICC Results (Correlation between the two blind observers)

\begin{tabular}{lll} 
Measurement Period & ICC (\%95C) & p \\
Before abrasion & $0.999(0.999-1.000)$ & $<0.001$ \\
After abrasion & $1.000(1.000-1.000)$ & $<0.001$ \\
\hline
\end{tabular}

Both the type of composite and the finishing and polishing material, were considered effective factors for abrasion ( $p=0.014, p<0.001$, respectively). Moreover, polishing material was found a more effective factor than composite. However, composite - polishing material combination was not considered an effective factor on abrasion ( $p=0.533)$.

The average abrasiveness observed for the Sof-Lex Disc system for $120 \mathrm{~s}$ of application, was $91.25 \mu \mathrm{m}$, whereas it was 24-36 $\mu \mathrm{m}$ for Enhance/Pogo, Optragloss, and Twist Dia for $60 \mathrm{~s}$ of application (Table 3).

Table 3. Descriptive Statistics and Multiple Comparisons Regarding Composites and Polishing Materials. The Level of Abrasion was Defined as $\mu \mathrm{m}$.

\begin{tabular}{lccc} 
Polishing Material & \multicolumn{2}{c}{ Composite } & Total \\
& $\begin{array}{c}\text { Tetric Evo } \\
\text { Ceram Bulk Fill }\end{array}$ & $\begin{array}{c}\text { IPS Empress } \\
\text { Direct }\end{array}$ & \\
\cline { 2 - 4 } Enhance/Pogo & $24.10 \pm 13.45^{\mathrm{x}}$ & $36.20 \pm 13.05^{\mathrm{x}}$ & $30.15 \pm 14.32^{\mathrm{a}}$ \\
\hline SoftLex Disc & $77.30 \pm 38.40^{\mathrm{x}}$ & $105.20 \pm 52.92^{\mathrm{x}}$ & $91.25 \pm 47.22^{\mathrm{b}}$ \\
Optragloss & $29.50 \pm 11.72^{\mathrm{x}}$ & $43.70 \pm 20.68^{\mathrm{x}}$ & $36.60 \pm 17.91^{\mathrm{a}}$ \\
\hline Twist Dia & $22.30 \pm 6.60^{\mathrm{x}}$ & $26.30 \pm 10.47^{\mathrm{x}}$ & $24.30 \pm 8.76^{\mathrm{a}}$ \\
\hline Total & $38.30 \pm 30.84^{\mathrm{A}}$ & $52.85 \pm 42.26^{\mathrm{B}}$ & \\
\hline
\end{tabular}

$A-B$ : No significant difference was found between the composites with the same letter; $a-b$ : No significant difference was found between the finishing and polishing systems with the same letter; $x$ : No significant difference was found for the composite and finishing and polishing system interactions with the same letter.

In terms of composite materials, IPS Empress Direct (52.85 \pm 42.26 ) presented significantly a greater level of abrasion than Tetric Evo Ceram Bulk Fill $(38.30 \pm 30.84)(p<0.001)$. In terms of finishing and polishing materials, Sof-Lex Disc (91.25 \pm 47.22) presented a significantly greater level of abrasion among all $(p<0.001)$ (Table 3$)$. There was no significant differences between Enhance/Pogo - Optragloss $(p=0.859)$, Enhance/Pogo - Twist Dia $(p=0.891)$, and Twist Dia - Optragloss $(p=0.440$ ) (Table 3$)$. The combination of SofLex Disc with IPS Empress Direct showed the highest level of abrasion (105.20 \pm 52.92), whereas the combination of Twist Dia with Tetric Evo Ceram Bulk Fill showed the lowest (22.30 \pm 6.60 ) (Table 3).

\section{DISCUSSION}

The abrasiveness of the finishing and polishing materials is very important, as the objective in composite restorations is to obtain the maximum surface smoothness with minimum surface material loss, clinically, especially when performing the additive layering technique rather than the subtractive technique $(22,23)$. Accordingly, several previous studies have observed the effectiveness of composite polishing systems on surface smoothness or color stability $(5-9,12,13,20$,
24-26). However, there is a lack in the studies regarding the evaluation of the level of abrasiveness of these materials. The method used to monitor the quantitative abrasiveness of finishing and polishing systems in the present study was not common. But, monitoring with the contact type digital micrometer, was previously used in vitro and in vivo, for evaluating bruxism-related incisal hard tissue loss quantitatively, as the control method $(16,17)$.

The type of the polishing material was reported to influence the final surface roughness, however, the influence for the type of composite material is controversial $(26,27)$. With regard to our results, the level of abrasion also varied among the composite finishing and polishing systems. Also, the level of abrasion varied among the composite types. Therefore, the $h_{1}$ hypotheses were accepted. However, the finishing and polishing material was considered a more effective factor influencing the level of abrasion compared to the composite type.

Current composite polishing systems in the market include only a single step or up to 4 steps with various grit sizes $(11,20,27,28)$. Moreover, some of these systems include only polishing materials with only fine grits, whereas, some include both finishing and polishing materials with fine and coarse grits. The systems including only composite polishing materials might also be combined with another material that can be used for the finishing procedure. Therefore, these should be taken into consideration for the comparison of the effectiveness as well as the abrasiveness of these systems. It has been shown that single-step polishing systems can be as effective as multi-step techniques, according to the finishing quality before the polishing $(9,20,26)$. Fine diamond burs, tungsten carbide burs, Arcansas burs, or rough polishing discs can be used as additional finishing materials to smoothen the composite surface $(9,29)$. A greater level of abrasiveness was reported for the finishing materials than the polishing materials (9). All the composite polishing systems in the present study included finishing and polishing steps to obtain a fair evaluation. According to the the literature, the polishing time for even the same polishing system may vary from 5 to 40 seconds (10). Whereas, only $5 \mathrm{~s}$ was reported to be enough for the greatest improvement on surface roughness, clinically, depending on the press-on force, type and shape of the finishing and polishing material, and also type of the resin composite (10). In this study, all systems were used at $10.000 \mathrm{rpm}$ (4) and dry conditions according to the instructions of the manufacturers. As the surface roughness, as well as the abrasiveness, are time-dependent (10), each step in the systems was used equally for $30 \mathrm{~s}$ to evaluate the total abrasive effect of each step of the system and also to achieve a standardized and maximum surface smoothness.

The effectiveness in the surface smoothness and the level of abrasiveness might not be directly proportional every time and sometimes might even be inversely proportional. Regarding the polishing material, the flexibility of the material and the hardness and grain size of the abrasive particles influence the polishing quality, as well as the level of abrasiveness (26, 
$29,30)$. The grain size of the abrasive particles should be harder than the filler particles of the material for an effective finishing and polishing procedure $(25,29,30)$. Otherwise, the polishing material removes the organic matrix from the surface and the filler particles will remain as protrusions, open to staining (27). Therefore, synthetic rubber, silicon carbide, aluminum oxide $\left(\mathrm{Al}_{2} \mathrm{O}_{3}\right)$, or diamond particles were generally used as the abrasive particles in many composite finishing and polishing systems $(14,29,31)$. Recently, a new two-step diamond-embedded polishing system Optragloss, including both finishing and polishing materials, was introduced with the claim of effectiveness for polishing of both resin composite and ceramic restorations, clinically. It might be interpreted that, this system includes abrasive particles harder than the hardness of ceramic materials, which might increase the level of abrasion for resin composite materials. In this study, one $\mathrm{Al}_{2} \mathrm{O}_{3}$ embedded, one $\mathrm{Al}_{2} \mathrm{O}_{3}$ and diamond embedded, and two diamond-embedded finishing and polishing systems were used to evaluate the level of abrasiveness on resin composites. According to the results, significantly the greatest level of abrasion was observed for the $\mathrm{Al}_{2} \mathrm{O}_{3}$ embedded Sof-Lex Disc system ( $p<0.001$; Table 3). In terms of the surface smoothness, the previous gold standard considered Sof-Lex Discs system $(20,25,31)$, had probably a disadvantage regarding the level of abrasiveness, due to the containing of a $55 \mu \mathrm{m}$ grit size disc. Also, the number of steps, as well as the total application time for the Sof-Lex Disc system, were two-times longer (4 steps / total of $120 \mathrm{~s}$ ) than the other systems ( 2 steps/total of $60 \mathrm{~s}$ ), which might have influenced the outcome. Therefore, it might be interpreted that, the abrasiveness of a finishing and polishing system was grit size and also finishing and polishing step dependent. Accordingly, it might be better to decide the number of steps to use in a finishing and polishing system, according to the smoothness of the restoration surface rather than the instructions for use. To reduce the level of abrasiveness, after evaluating the level of surface smoothness of the restoration, it might be better to use the 4-step Sof-Lex Disc system as a 3 -step system, by extracting the coarse disc $(55 \mu \mathrm{m})$, as some researchers did previously $(11,19)$.

Regarding the results, an unexpected outcome was about the 2-step composite and ceramic polishing system, the Optragloss. Although the observed abrasiveness of OptraGloss system (36.60 \pm 17.9 ) was higher than the Enhance/Pogo system (30.15 \pm 14.32$)$, and followed by the Twist Dia system $(24.30 \pm 8.76)$, there was no significant difference among these polishing systems ( $p<0.05$; Table 3 and 5 ). Marigo et al. reported that the type of the abrasive particles is an effective factor for the surface gloss (31). Unlike the number of steps, the harder abrasive particles in Optragloss did not significantly affect the level of abrasion. However, although it was not statistically significant, there was a quantitatively higher level of abrasiveness for OptraGloss, compared to the Enhance/Pogo and Twist Dia (Table 3). This difference might be because of the use of the high grain, dark blue, diamond embedded cup with greater abrasive particle hardness, which was suggested for the polishing of zirconium oxide $\left(\mathrm{ZrO}_{2}\right)$ and lithium disilicate glass-ceramic $\left(\mathrm{LS}_{2}\right)$ materials according to the manufacturer's instructions $(29,30)$. Moreover, the cup shape might have an affect to enhance the abrasiveness, in agreement with Heintze et al. (4). But, without using the cup with coarse grit, only the light blue spiral wheel with fine grit can not be enough for both finishing and polishing procedures of resin composites in this system. Therefore, in the present study, both cup and spiral wheel in OptraGloss were used as a two-step finishing and polishing system. Nevertheless, the abrasiveness was not different compared to Enhance/Pogo $(p=0.859)$ and Twist Dia $(p=0.440)$ systems.

The quantitatively greater level of abrasiveness for Enhance/ Pogo compared to Twist Dia, might be because of the differences in the abrasive particle type and size in these systems (Table 3) (26). Enhance/Pogo contains both the $\mathrm{Al}_{2} \mathrm{O}_{3}(40 \mu \mathrm{m})$ and diamond $(7 \mu \mathrm{m})$ abrasive particles (11), whereas Twist Dia only includes diamond (14 $\mu \mathrm{m}$ and $10 \mu \mathrm{m})$ particles (12), which might explain the greater abrasiveness of Enhance/Pogo for equal application times (26). Also, the spiral wheel shape of Twist Dia polishing materials might have reduced the press-on force, in agreement with Heintze et al. (4), and thereby, reduced the level of abrasiveness. According to Heintze et al. (4), other than press-on force advantage, the spiral wheels might have a good advantage for clinical application on curved dental surfaces. The shape might also effect the greater abrasiveness of the Sof-Lex Disc system in the present study. In accordance with Heintze et al. (4), the shape of the polishing system was considered an influencive factor for the effectiveness, in various researches, previously $(10,26,28)$. Sof-Lex Disc system included flat flexible discs, while other systems included rubber cups and/or flexible spiral wheels, which were reported to act as more pressure absorbers compared to the elastic paper $\operatorname{discs}(4,26,28)$. The discs and spiral wheels generally bend and counteract the increase in pressure while performing, whereas they act more rigidly while polishing the cups (10). However, regarding our results, this pressure absorbance factor might have not been as effective as the finishing and polishing step factor to inhibit the greater level of abrasiveness of the discs. Because a greater level of abrasion was observed for the Sof-Lex Disc system among all. Additionally, the material surfaces were flat in this in vitro study, and considering the round dental surfaces, the abrasiveness of the disc-shaped materials might be much higher, clinically $(26,31)$.

The spiral wheels such as Twist Dia and Sof Lex Spiral (3M, St. Paul, MN, USA) were considered as effective as the 4-step Sof-Lex Disc system, regarding the color stability of resin composites, with a shorter polishing time advantage, recently (26). However, only 3-4 \% of the dental practitioners in the US were reported to prefer spiral-shaped materials (4). Accordingly, the spiral shaped polishing materials with shorter application time, low level of abrasiveness, and good adaptation on curved dental surfaces might be preferred in daily clinical practice confidently.

Regarding the resin composite materials used, significantly a greater level of abrasion was detected for IPS Empress Direct 
(52.85 \pm 42.26$)$ compared to Tetric Evo Ceram Bulk Fill (38.30 $\pm 30.84)(p<0.001$; Table 3$)$. Both of the resin-based materials used in this study were nano-hybrid composites with a similar organic matrix, whereas the filler contents were not the same (Table 1). The surface micro-morphology of resin composites following the finishing and polishing procedures was reported to be influenced by the size, amount, and hardness of the filler particles, previously $(26,30)$. The filler ratio of IPS Empress Direct (78.1\% wt) and Tetric EvoCream Bulk Fill (80\% wt) materials was close, therefore the $1.9 \%$ wt difference can not be the only reason of Tetric EvoCream Bulk Fill be more resistant to abrasion, concerning our results (Table 1). However, the prepolymers (17\% wt) in Tetric EvoCeram Bulk Fill which increase the strength and reduce the volume shrinkage (15), are not included in IPS Empress Direct enamel shades. Also, IPS Empress Direct enamel shades do not contain additional coarse $(0.7 \mu \mathrm{m})$ barium glass fillers, unlikely which Tetric EvoCeram contains to increase the strength (15). Although the coarse barium glass fillers were reported to cause increased surface roughness previously (15), in terms of the level of abrasion, it might act as an advantage. The lack of these two fillers might be the reason for the greater level of abrasion for IPS Empress Direct in our study. Additionally, a photo-initiator system (Ivocerin a dibenzoyl germanium compound) in Tetric EvoCeram Bulk Fill might contribute to the abrasion resistance by enhancing the depth of cure as well as the degree of conversion (Table 1) (32). In a previous study, the surface properties were considered statistically similar for IPS Empress Direct enamel and Tetric EvoCeram Bulk Fill composites, after toothbrush abrasion (33). This result might be interpreted that, the level of abrasion for both composites were similar. Opposingly, according to our results, the level of abrasion was higher for IPS Empress Direct enamel. Also, the combination of the most abrasive considered 4-step Sof-Lex Disc system with IPS Empress Direct composite presented the greatest level of abrasion. On the contrary, the combination of the least abrasive considered two-step Twist Dia with Tetric Evo Ceram Bulk Fill presented the lowest level of abrasion (Table 3).

Standardization in the press-on force has been an important topic for the in vitro studies about polishing materials. Antonson et al. reported no statistical difference among male and female operators for polishing previously (11), whereas Heintze et al. considered female dentists using lower press-on force than male dentists and the average moderate hand pressure as $2 \mathrm{~N}$, more recently (4). In this study, to calibrate the press-on force and micrometer measurements during the finishing and polishing procedures, a preliminary study was undergone by two blind female operators, on 20 other samples. Micrometer calibration was achieved by measuring the thicknesses of the 20 samples three times, before and after abrasion procedures. The average values were considered for the anlayses. Also, a perfect interclass correlation was observed for both measurement periods (0.999 and 1.000; Table 1), therefore the real polishing procedures were initiated with operator 1 .
In the present study, the assessment of the effectiveness of dental polishing systems was generally tested in vitro on flat specimen surfaces, using dental handpieces, with a defined rotation speed and a predefined polishing time (4). However, the polishing procedure is a dynamic task, clinically (4). Especially for the occlusal surfaces, as the material moves on curved tooth surfaces, the press on force also fluctuates depending on the angle of the curve and the shape and hardness of the material $(4,10)$. Therefore, the conditions of in vitro studies might not simulate the clinical conditions. It might be better to monitor the press-on force while performing abrasion procedures for further studies. Also in the present study, the finishing and polishing systems were used including all the steps to compare the total effects of the systems. However, reducing the number of steps may alter the outcome clinically. Moreover, more proven abrasion monitoring methods such as optic profilometer, AFM, and SEM should be used for further studies to crosscheck the outcomes. Also, resin composites in different brands and types, and finishing and polishing materials in different brands and shapes might influence the level of abrasiveness.

\section{CONCLUSIONS}

Within the limits of this study, both types of composite and finishing and polishing material were considered effective factors for surface abrasion. The 4-step Sof-Lex Disc system presented the greatest level of abrasiveness (91 $\mu \mathrm{m}$ on average) among all, for 120 seconds of application. The abrasiveness of Enhance/Pogo, Optragloss, and Twist Dia was similar and ranged between $24-36 \mu \mathrm{m}$ on average, for 60 seconds of application. IPS Empress Direct presented a greater level of abrasion than Tetric Evo Ceram Bulk Fill regarding finishing and polishing procedures on equal terms.

\section{Conflict of Interest}

The manuscript has been read and approved by all the authors. No potential conflict of interest was reported by any of the authors in this study.

\section{REFERENCES}

[1] LeSage B. Finishing and polishing criteria for minimally invasive composite restorations. General Dent 2011;59(6):422-428.

[2] Bashetty $K$, Joshi $S$. The effect of one-step and multi-step polishing systems on surface texture of two different resin composites. J Conserv Dent 2010;13(1):34-38.

[3] Senawongse $P$, Pongprueksa P. Surface roughness of nanofill and nanohybrid resin composites after polishing and brushing. J Esthet Restor Dent 2007;19(5):265-275.

[4] Heintze SD, Reinhardt M, Müller F, Peschke A. Press-on force during polishing of resin composite restorations. Dent Mater 2019;35(6):937-944.

[5] Jefferies SR. Abrasive finishing and polishing in restorative dentistry: A state-of-the-art review. Dent Clin North Am 2007;51(2):379-397. 
[6] Krejci I, Lutz F, Boretti R. Resin composite polishing-Filling the gaps. Quintessence Int 1999;30(7):490-495.

[7] Watanabe T, Miyazaki M, Takamizawa T, Kurokawa Hrikuta A, Ando S. Influence of polishing duration on surface roughness of resin composites. J Oral Sci 2005;47(1):21-25.

[8] Terry DA. Finishing and polishing adhesive restorations: Part II. Pract Proced Aesthet Dent 2005;17(8):545-548.

[9] Daud A, Gray G, Lynch CD, Wilson NHF, Blum IR. A randomised controlled study on the use of finishing and polishing systems on different resin composites using 3D contact optical profilometry and scanning electron microscopy. J Dent 2018;71:25-30.

[10] Heintze SD, Forjanic M, Rousson V. Surface roughness and gloss of dental materials as a function of force and polishing time in vitro. Dent Mater 2006;22:146-165.

[11] Antonson SA, Yazici AR, Kilinc E, Antonson DE, Hardigan PC. Comparison of different finishing/polishing systems on surface roughness and gloss of resin composites. J Dent 2011;39:9-17.

[12] Kemaloglu H, Karaçolak G, Türkün LŞ. Can Reduced-Step Polishers Be as Effective as Multiple Step Polishers in Enhancing Surface Smoothness? J Esthet Restor Dent 2017;29(1):31-40.

[13] Kocaağaoğlu H, Aslan T, Gürbulak A, Albayrak H, Taşdemir Z, Gumus $\mathrm{H}$. Efficacy of polishing kits on the surface roughness and color stability of different composite resins. Niger J Clin Pract 2017;20(5):557-565.

[14] Wilder Jr AD, Swift Jr EJ, May Jr KN, Thompson JY, McDougal RA. Effect of finishing technique on the microleakage and surface texture of resin-modified glass ionomer restorative materials. J Dent 2000;28(5):367-373.

[15] Takahashi R, Jin J, Nikaido T, Tagami J, Hickel R, Kunzelmann $\mathrm{KH}$. Surface characterization of current composites after toothbrush abrasion. Dent Mater J 2013;32(1):75-82.

[16] Korkut B, Tagtekin D, Murat N, Yanikoglu F. Clinical quantitative evaluation of tooth wear: a 4-year longitudinal study. Oral Health Prev Dent 2020;18:719-730.

[17] Korkut B, Yanikoglu F, Tagtekin D. In vitro assessment of dimensional alterations of worn human incisors. Med Sci 2015;4:218-222.

[18] Nayyer M, Zahid S, Hassan SH, Mian SA, Mehmood S, Khan HA, Kaleem M, Zafar MS, Khan AS. Comparative abrasive wear resistance and surface analysis of dental resin-based materials. Eur J Dent 2018;12(1):57-66.

[19] Stoddard JW, Johnson GH. An evaluation of polishing agents for composite resins. J Prosthet Dent 1991;65(4):491-495.

[20] Carneiro PM, Ramos TM, de Azevedo CS, de Lima E, de Souza $\mathrm{SH}$, Turbino ML, Cesar PF, Matos AB. Influence of finishing and polishing techniques and abrasion on transmittance and roughness of composite resins. Oper Dent 2016;41(6):634641.

[21] Dodge WW, Dale RA, Cooley RL, Duke ES. Comparison of wet and dry finishing of resin composites with aluminum oxide discs. Dent Mater 1991;1:18-20.

[22] Pontons-Melo JC, Garcia IM, Vargas M, Collares FM. Bioadditive and enameloplasty technique for restoring anterior esthetics: 54-month clinical follow-up. Quintessence Int 2020;51(8):622-629.

[23] Korkut B, Türkmen C. Longevity of direct diastema closure and recontouring restorations with resin composites in maxillary anterior teeth: A 4-year clinical evaluation. J Esthet Restor Dent 2020;33(4):590-604.

[24] Barutcugil Ç, Yildiz M. Intrinsic and extrinsic discoloration of dimethacrylate and silorane based composites. J Dent 2012;40(1):57-63.

[25] Sarac D, Sarac YS, Kulunk S, Ural C, Kulunk T. The effect of polishing techniques on the surface roughness and color change of composite resins. J Prosthet Dent 2006;96(1):33-40.

[26] Korkut B. Cila sistemlerinin mikrohibrit ve nanohibrit rezin kompozitlerin renklenmesi üzerine etkisinin değerlendirilmesi. Turkiye Klinikleri J Dental Sci 2020;1:1-12. Doi: 10.5336/ dentalsci.2020-77511

[27] Reis AF, Giannini M, Lovadino JR, dos Santos Dias CT. The effect of six polishing systems on the surface roughness of two packable resin-based composites. Am J Dent 2002;15:193197.

[28] Turkun LS, Turkun M. The effect of one-step polishing system on the surface roughness of three esthetic resin composite materials. Oper Dent 2004;29(2):203-211.

[29] Avşar A, Yüzbaşığlu E, Sarac D. The effect of finishing and polishing techniques on the surface roughness and the color of nanocomposite resin restorative materials. Adv Clin Exp Med 2015;24(5):881-890.

[30] Ergücü Z, Türkün LS. Surface roughness of novel resin composites polished with one-step systems. Oper Dent 2007;32(2):185-192.

[31] Marigo L, Rizzi M, LaTorre G, Rumi G. 3D surface profile analysis: Different finishing methods for resin composites. Oper Dent 2001;26(6):562-568.

[32] Alrahlah A, Silikas N, Watts DC. Post-cure depth of cure of bulk fill dental resin-composites. Dent Mater 2014;30(2):149-154.

[33] Lai G, Zhao L, Wang J, Kunzelmann KH. Surface properties and color stability of incrementally-filled and bulk-fill composites after in vitro toothbrushing. Am J Dent 2017;30(5):262-266.

How to cite this article: Korkut B, Unal T. The Assessment of the Abrasiveness for Resin Composite Finishing and Polishing Systems. Clin Exp Health Sci 2021; 11: 529-535. DOI: 10.33808/ clinexphealthsci.852450 